\title{
Impact of the Tobacco Price Support Program on tobacco control in the United States
}

\author{
Ping Zhang, Corinne Husten
}

\begin{abstract}
Objectives-To evaluate the impact of the United States Tobacco Price Support Program (TPSP) on domestic cigarette consumption and the potential political impact of the TPSP on efforts to reduce smoking.
\end{abstract}

Data sources-Published studies known to the authors and a search of AGRICOLA from 1980 to 1996.

Study selection-Studies published in a refereed journal or research reports published by an accredited university or institution.

Data synthesis-The TPSP decreases cigarette use by increasing the price of cigarettes. The price increase resulting from the TPSP, however, is small-about one cent per pack. The resulting decrease in cigarette consumption is also very modest-an estimated $0.23 \%$. However, the TPSP creates tobacco quota owners, who have a strong financial interest in opposing measures to reduce smoking. The TPSP also changes the political influence of tobacco farmers by keeping a large number of small farmers in tobacco production.

Conclusions-The negative impact of the TPSP (opposition to tobacco control measures) is probably greater than the positive impact of the programme (reducing smoking). Therefore, the net impact of the TPSP on tobacco control efforts is likely to be negative.

(Tobacco Control 1998;7:176-182)

Division of Adult and Community Health, Chronic Disease

Prevention and Health

Promotion, US

Centers for Disease

Control and

Prevention, Atlanta,

Georgia, USA

P Zhang

Office on Smoking and

Health

C Husten

Correspondence to:

Dr P Zhang, Division of

Adult and Community

Health, National Center for

Chronic Disease Prevention

and Health Promotion, US

Centers for Disease Control

HWY, NE, Mail Stop K-45,

Atlanta, Georgia 30341,

USA.

PAZ2@cdc.gov reasons. ${ }^{2}$ The Department of Agriculture in the United States (USDA) currently provides direct support for 31 specific commodities including tobacco. ${ }^{3}$

The systems of supports vary across agricultural commodities. Each programme is uniquely designed to fit the production, handling, storage, and marketing characteristics of that commodity, although there are substantial similarities among some programmes. ${ }^{3}$ The federal farm programme for tobacco is the Tobacco Price Support Program (TPSP) (described in detail in the next section).

The level of federal support also differs across agricultural commodities. When commodity support benefits as a percentage of the total value of production between 1994 and 1996 is used as a measure, tobacco ranked sixth among the 10 commodities examined by Womack and Becker. ${ }^{3}$ The benefit derived from the government programme for tobacco farmers was $20 \%$ of their production value. For rice farmers, it was $65 \%$, for sugar cane farmers $34 \%$, for peanut farmers $32 \%$, for wheat farmers $22 \%$, for cotton farmers $21 \%$, and for soybean farmers nothing at all. In terms of costs to taxpayers, however, tobacco cost the least. There have been no taxpayer dollars spent on operating the Tobacco Price Support Program (except the administrative expenses of the programme and crop insurance subsidy) since 1983. The net government expenditure on tobacco (measured as the administrative expenses of the programme and crop insurance subsidy minus the contribution of tobacco farmers to the national deficit reduction) was, on average, $\$ 39.5$ million per year between 1994 and $1996 .{ }^{45}$ In comparison, the rice programme costs taxpayers about $\$ 1000$ million per year for only about 18000 farmers. ${ }^{6}$

Tobacco use has been identified as the single most preventable cause of death in the United States. ${ }^{7}$ It is estimated that smoking causes about 430700 deaths per year in the United States. ${ }^{8}$ The total economic cost of smoking to society has been estimated at about $\$ 100000$ million per year. ${ }^{10}$ On the other hand, consumers spent $\$ 48700$ million on tobacco products in 1995, and the tobacco industry employed about 500000 people directly. ${ }^{11}$ Exports and imports of tobacco leaf and tobacco products also generated a $\$ 5300$ million trade surplus for the United States in 1996. ${ }^{12}$ 
While the federal government supports tobacco farmers through the TPSP and the other federal programmes such as the crop insurance programme and agricultural research, it also attempts to reduce tobacco use by publicly acknowledging its adverse effect on health, by allocating funds to the Public Health Service for scientific research on smoking and public health education on its effects, and by issuing regulations to discourage smoking. ${ }^{13}$ In this study, we evaluate the impact of the TPSP on tobacco control. The TPSP affects many aspects of the tobacco industry including tobacco production, domestic cigarette consumption, exports and imports of tobacco and cigarettes, and the tobacco farming community in general. ${ }^{1{ }^{14} 15}$ For example, the TPSP increases the price of American tobacco in the world market and this higher price leads to a reduction in exports of tobacco leaf. Also, the TPSP guarantees a higher revenue for tobacco farmers, and this secured revenue and its ripple effects could have a significant impact on the prosperity of local communities where a large proportion of the local revenue is derived from tobacco farming. ${ }^{15}$ These broader effects are discussed elsewhere. ${ }^{261415}$ In this study, we focus our discussion only on these aspects of the TPSP that are most closely related to public health and tobacco control efforts. Specifically, we evaluate (a) the impact of the TPSP on domestic cigarette consumption and (b) the potential adverse political consequences of the TPSP on efforts to reduce smoking.

In a commentary, Warner ${ }^{16}$ discussed the relationship between the TPSP and tobacco control efforts. Using the 1984 study of Sumner and Alston, ${ }^{14}$ Warner reported that the TPSP increased the price of cigarettes by $2-3$ cents per pack. Warner also discussed the possible political consequences of the TPSP, such as the creation of political constituencies against tobacco control measures in Congress.

Our analysis differs from Warner's in two ways: it uses updated estimates of the impact of the TPSP on cigarette consumption and it examines how changes in cigarette use resulting from tobacco control efforts would affect the economic interests of the beneficiary groups of the TPSP. Knowledge of how tobacco control measures would affect the financial interests of tobacco farmers and quota owners will help the public health community to understand the attitude of these groups toward tobacco control efforts.

\section{Tobacco Price Support Program}

The TPSP, which is designed to support and stabilise tobacco prices, has been operated by the USDA since 1933 when Congress passed the first Agricultural Adjustment Act. ${ }^{1}$ The primary policy tools within the current TPSP are marketing quotas, price supports, and import restrictions. ${ }^{1}$

Marketing quotas control production by limiting the number of pounds of tobacco a farmer can market that are eligible for price support; excess sales are subject to prohibitive penalties. The national quota set by USDA is based on: (a) intended purchases by cigarette manufacturers; (b) average annual export for the three preceding years; and (c) the amount of tobacco needed to attain a specific reserve stock level. ${ }^{17}$ In addition, each year the Secretary of Agriculture can adjust the level of quota up or down by $3 \%$ of the calculated level.

The marketing quota of the TPSP began in 1938. Individual tobacco farmers were given quotas based on their historical production. ${ }^{17}$ The quota was tied specifically to the farmland; farmers not having a quota could grow tobacco only by purchasing or renting land that had one. In 1962, the programme was modified, and tobacco farmers can now rent or purchase a quota without renting or purchasing the land from the quota owner. ${ }^{17}$ However, there are restrictions on the leasing of quotas depending on the type of tobacco produced. For example, a quota for flue-cured tobacco generally cannot be leased, and burley tobacco quotas can be leased but not across county lines (except in Tennessee). ${ }^{17}$

The price support programme uses a loan system to ensure a minimum price for tobacco farmers. The Commodity Credit Corporation (CCC), which is an agency of the USDA, makes loans to farmer-owned cooperatives. The USDA sets the level of price support through an announced loan price, which varies according to the variety and grade of tobacco leaf. This loan price, the minimum price tobacco farmers receive, is guaranteed through a non-recourse loan mechanism. With a non-recourse loan, the collateral (in this case, tobacco leaf) is accepted as the full settlement of the debt.

Farmers sell cured tobacco to the highest bidder at an auction, unless the bids are below the loan price. In this case, the tobacco farmer is paid the loan price by a cooperative with money borrowed from the CCC. The newly purchased tobacco is then consigned to the cooperative, which redries, packs, and stores the tobacco as collateral for the CCC loan. The cooperative, acting as an agent for the CCC, later sells the tobacco with the proceeds going to repay the loan from the CCC. Losses occur if the cooperative must sell the collateral tobacco at a price insufficient to cover the outstanding loan principal plus interest. ${ }^{18}$

CCC losses were initially covered by the government with tax money. This was changed in 1982 when Congress passed the No-Net-Cost Act, which imposed an assessment fee on every pound of tobacco sold by tobacco farmers. The fee, which is shared by farmers and buyers, is deposited in an escrow account and used to reimburse the government for any loss resulting from the TPSP. ${ }^{17}$

Import restrictions limit the quantity of cheaper foreign tobacco coming into the American market to maintain a higher domestic price. The Omnibus Budget Reconciliation Act of 1993 required that cigarettes manufactured in the United States contain at least $75 \%$ American-grown tobacco, ${ }^{1}$ but this requirement was eliminated in September 1995 with adoption of the tariff rate quota. 
Under this mechanism, each major supplier country can export a specific amount of tobacco to the United States at a normal tariff rate; shipments in excess of this quota are subjected to a $350 \%$ duty. However, most of the duty may be refunded if the tobacco is used to manufacture cigarettes that are exported by the United States. ${ }^{17}$ Thus, with the 1995 provision, tobacco companies have substantial freedom to import tobacco above quota levels with few penalties. As a result, the provision does little to ensure the tobacco companies use more American-grown tobacco.

\section{Impact of the TPSP on domestic cigarette consumption}

The primary purpose of controlling the tobacco supply is to keep prices high and relatively stable. ${ }^{17}$ If the demand for tobacco does not decline, prices will rise as the supply of tobacco is reduced. In their 1984 study, Sumner and Alston ${ }^{14}$ estimated that eliminating the TPSP would reduce the price of American tobacco by $17-30 \%$. A more recent study by Zhang, Husten, and Giovino concluded that the TPSP has increased the price of tobacco by $32-40$ cents per pound (70-88 cents per $\mathrm{kg} ; 18-23 \%$ of the price between 1990 and 1994). (Unpublished manuscript obtainable from $\mathrm{PZ}$ on request. The study consists of the economic model and data used to derive the estimate of the impact of the TPSP on domestic cigarette consumption.)

The importance of domestic tobacco as a cost element in the retail price of cigarettes has been declining steadily over time. One reason is that the quantity of tobacco required to produce a unit of cigarettes has decreased because: (a) filter-tipped and smaller-diameter cigarettes have become more popular; (b) new technologies that allow tobacco stems to be blended into cigarettes are being employed; and (c) tobacco sheets are being used more efficiently. ${ }^{19}$ A second reason that domestic tobacco is a lesser factor in the retail price of cigarettes is that manufacturers are using cheaper imported tobacco. ${ }^{15}$

From 1980 to 1991, wholesale cigarette prices increased $267 \%$; average retail prices $187 \%$ (from $\$ 0.62$ to $\$ 1.78$ per pack). During the same period, the farm price of tobacco leaf rose only $18 \%$. Domestic tobacco's share of total tobacco use fell from $71 \%$ to $65 \%$. As a result, the share of the farm value of domestic tobacco in total cigarette retail value declined from $7 \%$ in 1980 to only $3 \%$ in $1991 . .^{15} 19$

The American cigarette manufacturing industry is oligopolistic, with five manufacturers controlling almost the entire market. ${ }^{20} \mathrm{~A}$ recent study ${ }^{21}$ showed that cigarette manufacturers price-discriminate by state but the effect was not large relative to the final retail price. Assuming that tobacco price increases resulting from the TPSP would be fully passed on to the price of cigarettes at the retail level, Sumner and Alston estimated that if the programme increased tobacco price by $30 \%$, the price of cigarettes would increase by $3 \%$ or about two cents per pack in 1983. Using a price elasticity of -0.3 for cigarettes, they estimated that the higher cigarette price would reduce cigarette consumption by about $1 \%$.

Considering the decrease in domestic tobacco's share of total tobacco used, and using more updated price elasticities of supply and demand for American tobacco, Zhang, Husten, and Giovino (unpublished manuscript-see above) recently estimated that a 40 -cent per pound ( 88 cents per $\mathrm{kg}$ ) increase in tobacco price resulting from the TPSP would lead to a price increase of only one cent per pack of cigarettes. At this higher price, they estimated the resulting decline in cigarette consumption to be $0.23 \%$ or 56 million packs of cigarettes in 1994. Assuming that half of this reduction came from the decrease in the number of smokers, these researchers estimated that the TPSP reduced the number of smokers by 66500 or $0.14 \%$ of total smokers in 1994. Per smoker, they estimated a reduction of 12 cigarettes (or $0.14 \%$ ) annually.

\section{Potential political impact of the TPSP on efforts to reduce smoking}

TOBACCO QUOTA OWNERS AND EFFORTS TO REDUCE SMOKING

The adverse impact of the TPSP on efforts to control smoking is indirect, and the programme must be evaluated in the context of policy formulation and implementation. ${ }^{16}$ Perhaps the most important potential political effect of the TPSP on tobacco control is that it has created quota owners, who have a strong financial interest against efforts to reduce smoking. In 1993, of the 375073 tobacco quota holders, only about one a grew tobacco. ${ }^{18}$ Thus, the TPSP has produced about 250000 non-farmer quota owners, largely concentrated in the six biggest tobacco producing states, with a potential stake on tobacco control efforts.

Quota owners are the major beneficiaries of the TPSP. Marketing quotas represent a right, originally bestowed by the federal government; this right allows the owners to sell a limited amount of tobacco at a guaranteed minimum price. This price, which is generally higher than the price would be without the TPSP, provides the owner with a potential stream of income over the years. The expectation of a future profit accruing from the quota transforms the quota itself into an asset with value that can be sold or rented. ${ }^{22}$

The value of the quota is reflected in its price and the rent paid for it. The average sale price of quota for burley type of tobacco was estimated at $\$ 1.79$ per pound ( $\$ 3.94$ per $\mathrm{kg}$ ) in $1995 .^{23}$ As the total quota was 1500 million pounds ( 700 million $\mathrm{kg}){ }^{23}$ the market value of the total national tobacco quota was $\$ 2700$ million in 1995. The average rent paid for quota in most tobacco production areas currently ranges between $\$ 0.40$ and $\$ 0.50$ per pound ( $\$ 0.88-1.10$ per $\mathrm{kg}) .{ }^{1}$ Rent revenues of the quota for all quota owners (those who lease their quotas to others and these who use the quota themselves), based on a total quota of 1500 million pounds (700 million $\mathrm{kg}$ ) in 1995 , ranged from $\$ 592$ to $\$ 741$ million. 
Measures to reduce smoking are expected to reduce demand for tobacco and to change the quota revenues for quota owners. ${ }^{24}$ Whether these revenues will become larger or smaller depends on which of the three possible scenarios becomes the USDA response to a decline in demand for cigarettes ${ }^{24}$ : (1) fix the quantity of tobacco quota and allow the level of price supports to fall; (2) maintain the level of price support and reduce the amount of tobacco quota; or (3) simultaneously reduce the level of price support and the amount of tobacco quota.

Sumner and Wohlgenant ${ }^{24}$ estimated the magnitude of the change in revenues for quota owners that would result from cigarette tax increases and smoking restrictions; in 1995 Brown $^{25}$ updated their study, assuming a 75 -cent increase in cigarette tax per pack and an increase in the smoking restriction index of 0.5 . (The smoking restriction index is a measure of smoking restrictions in public places. If a state restricts smoking at worksites, it receives a score of 1 . States that restrict smoking in restaurants but not in private worksites receive a score of 0.75 . If a state does not restrict smoking in private worksites or restaurants but restricts smoking in at least four other public places, such as public buses and trains, it receives a score of 0.5 . States with one to three of these relatively minor restrictions in place get a score of 0.25 , and states with no regulation in place receive a score of 0 .)

Brown predicted that quota revenues would be reduced by $\$ 116$ million if the government chose policy 1 . According to Brown, choosing policy 2 would mean that quota revenues would increase by $\$ 22$ million; policy 3 would yield an outcome somewhere between the first two results (table 1). A detailed analysis of the impact of the different policy choices on revenues for quota owners as well as for tobacco farmers is provided in the appendix.

Because quota revenues could either increase or decrease in response to a decline in demand for tobacco depending on the policy (reduce quota or level of price support or both) which the government selects, attitudes of quota owners toward cigarette tax increases and smoking restrictions should depend on their perception of the government's response. The government has chosen policy option 1 in the past. For example, the level of price support was reduced by $15 \%$ in response to a market condition of excess supply of tobacco in 1986. ${ }^{1}$ Another way of reducing the level of price support is to decrease the real price level of support. Between 1986 and 1994 the level of price support after adjusting for inflation declined $19 \% .{ }^{1}$ In addition, a negative attitude toward the quota owner could potentially put pressure on policy makers if they choose a policy which favours the quota owner. For example, the quota system used in peanut and tobacco production has already been criticised for providing a windfall benefit to a small group of quota owners. ${ }^{22}$ This suggests that quota owners can reasonably expect that their revenues would decline from measures that reduce demand for cigarettes. Thus, it would be in their economic interest to oppose tobacco control measures.

\section{TOBACCO FARMERS AND EFFORTS TO REDUCE} SMOKING

A second indirect effect of the TPSP on tobacco control results from its impact on the number of tobacco farmers, the size of tobacco farms, and the geographical distribution of tobacco farms. The net impact of the TPSP on the number of farmers engaged in growing tobacco is not clear; the programme exerts both positive and negative effects. On the one hand, it decreases the number of farmers by reducing tobacco production; on the other hand, it keeps the number of tobacco farmers artificially high by slowing the process of consolidating small tobacco farms into fewer and larger operations.

By creating a higher tobacco price, the TPSP keeps small, inefficient farmers in tobacco production. Although the 1962 change in the programme, which permitted quota sale and lease within a county, has promoted production efficiency by facilitating a shift from small, high-cost operations to larger, low-cost operations within the same county, prohibition on sales and leases across county lines has still limited the production shift between counties. ${ }^{14}$ In addition, the cost of renting quotas represents financial resources that could otherwise be used by efficient farms to expand their scale of operation.

Measures to reduce smoking usually reduce farmers' revenues; at best they are revenue neutral. Again, assuming a 75-cent increase in cigarette tax per pack and an increase in the smoking restriction index of 0.5, Brown $^{25}$ found that revenues for tobacco farmers would not change under federal policy 1 . In contrast, he found that revenues for farmers would fall by $\$ 264$ million if the government chose policy 2 and that revenue would fall by a smaller amount if the government chose policy 3 (table 1). Given

Table 1 Estimated changes in revenues for tobacco quota owners and tobacco farmers resulting from cigarette tax increases and additional smoking restrictions*

\begin{tabular}{llcl}
\hline Government policy responses & $\begin{array}{l}\text { Changes in revenues for } \\
\text { quota owners (\$ million) }\end{array}$ & $\begin{array}{l}\text { Changes in revenues for } \\
\text { farmers (\$ million) }\end{array}$ & $\begin{array}{l}\text { Changes in combined revenues } \\
\text { for quota owners and farmers } \\
\text { (\$ million) }\end{array}$ \\
\hline $\begin{array}{l}\text { Fix tobacco quota and reduce tobacco price } \\
\quad \text { support level }\end{array}$ & -116 & 0 & -116 \\
$\begin{array}{l}\text { Maintain tobacco price support level and } \\
\quad \text { reduce tobacco quota }\end{array}$ & +22 & -264 & -242 \\
$\begin{array}{l}\text { Reduce tobacco price support level and } \\
\text { tobacco quota simultaneously }\end{array}$ & -116 to +22 & -264 to 0 & -242 to -116
\end{tabular}

$\star$ Assuming an increase in cigarette taxes by 75 cents/pack and in the smoking restriction index by 0.5 . 
the possibility of incurring substantial losses resulting from changes in federal tobacco policy following the implementation of measures to reduce smoking, farmers are not likely to be sympathetic to tobacco control efforts.

About $80 \%$ of tobacco farmers own their production quota either entirely or in part. ${ }^{1}$ These farmers derive revenues from both farm operations and from the value of their quota. Measures to reduce smoking would always have a negative impact on these farmers' revenues because the impact of tobacco control measures on the sum of the two revenues is always negative-for example, for policy 2, a $\$ 22$ million increase plus a $\$ 264$ million decrease equals a $\$ 242$ million decrease (table $1)$.

It is impossible to quantify the change in potential political impact of tobacco farmers on tobacco control measures as a result of the TPSP because one cannot know how the tobacco production sector would change in the absence of the programme. It appears that more tobacco would be produced and the size of tobacco farms would be larger without the TPSP, but how these large farmers would organise themselves and how effective they would be in influencing legislation is difficult to predict. (Larger production is the result of increasing sales in both domestic and export markets due to lower prices. Zhang, Husten, and Giovino (unpublished manuscript) estimated that without the TPSP, American tobacco production would be $47-68 \%$ greater than the current level, consistent with Sumner and Alston's prediction that tobacco production could be increased by $50-100 \%$ if the support programme were abolished. ${ }^{14}$ In addition, without the Tobacco Price Support Program, most of the small and inefficient farms would no longer be in production and thus the size of tobacco farm would be larger.)

Tobacco farmers have been able to exert influence against tobacco control policies. For example, during the announcement in the United States of the Food and Drug Administration's new regulations on cigarettes and smokeless tobacco on 21 August 1996, although there were many groups being affected negatively by the regulation, President Clinton singled out only tobacco farmers as a group. He promised farmers that the government would help them financially. The TPSP gives farmers a strong economic incentive to oppose tobacco control measures. Because the TPSP raises the price of American tobacco and reduces tobacco exports, tobacco farmers derive a larger proportion of their revenues from domestic tobacco use than they would without the programme. In addition, the TPSP may have contributed to the organisation of tobacco farmers. On the one hand, as a group, tobacco farmers are economically dependent on the programme. The programme benefit, which is measured as a percentage of the value of production between 1991 and 1994, was 20\%. ${ }^{3}$ On the other hand, public perceptions of the quota system are negative because it decreases efficiency, benefits only a small group of people, and reduces American competitiveness in world markets. ${ }^{22}$ Both of these factors could have the effect of bringing farmers together to fight for the programme's continuation. Tobacco farmers can use this "political infrastructure" not only to fight for the TPSP, but also to oppose other public policies that affect them negatively, such as tobacco control measures.

\section{Conclusion}

In this review, we reported that the impact of the Tobacco Price Support Program on smoking is small. The price per pack of cigarettes is increased by only about one cent as a result of the higher tobacco price induced by the TPSP, an increase that is estimated to reduce cigarette consumption by $0.23 \%$.

For proponents of tobacco control, the small beneficial effect of the TPSP must be weighed against the potential political influence of quota owners on opposing efforts to reduce smoking. In addition, we do not expect a larger political influence from tobacco farmers in the absence of the TPSP. Thus, it is very likely that the TPSP has strengthened potential political opposition to smoking control.

The key issue is whether the reduction in smoking attributable to the current TPSP exceeds the negative effect of the opposition to tobacco control measures generated by quota owners and tobacco farmers. Because the decrease in cigarette consumption resulting from the TPSP is less than the effect from a two-cent increase per pack in the federal excise tax, the effect of the TPSP on reducing smoking is minimal compared with the expected effect of virtually all tobacco policy measures currently under consideration. ${ }^{16}$ If the potential political forces attributable to the TPSP can block policies such as a cigarette tax increase or other tobacco control initiatives, the net impact of the TPSP on tobacco control would be negative.

Logically, cigarette manufacturers should be against the TPSP because a higher tobacco price increases their production costs and reduces cigarette consumption. However, tobacco manufacturers are not lobbying the federal government to abolish the TPSP. This suggests that the potential political benefit (active opposition of quota holders and tobacco farmers to tobacco control measures) of the TPSP for manufacturers is greater than the financial loss resulting from a higher domestic price of tobacco. We conclude that the negative impact of the TPSP (opposition to tobacco control measures) probably exceeds the positive impact of the programme (reducing smoking by lowering cigarette consumption).

We gratefully acknowledge Gary Giovino and Cathy Allen of the Office on Smoking and Health, Centers for Disease Control and Prevention, Atlanta, Georgia and the two anonymous reviewers for reviewing the earlier version of this manuscript and providing useful suggestions.

1 Grise, V N. Tobacco: background for 1995 farm legislation. Washington, DC: USDA, 1995. (Agricultural economic report no. 709.) 
2 Tweeten L. The twelve best reasons for a commodity program: why none stand scrutiny. Choices 1995; 2nd quart

3 Womach J, Becker G. Comparing levels of farm support across selected commodities. CRS report for Congress. Washington, DC: Congressional Research Service, 1995. (95-840 ENR.)

4 Womach J, Becker G. Tobacco-related programs and activities of the US Department of Agriculture: operation and cost. CRS report for Congress. Washington, DC: Congressional Research Service, 1997. (97-417 ENR.)

5 US Department of Agriculture. Tobacco situation and outlook report. Washington, DC: USDA, 1997. (TBS-239.)

6 Innes R. Politics and the public interest in farm policy: five litmus test issues. Choices 1995; 3rd quarter, 17-22.

7 US Department of Health and Human Services. Reducing the health consequences of smoking: 25 years of progress. A report of the Surgeon General, 1989. Rockville, Maryland: Public Health Service, Centers for Disease Control, Office on Smoking and Health, 1989. (DHHS Publication No (CDC) 89-8411.)

8 US Centers for Disease Control and Prevention. Cigarette smoking-attributable mortality and years of potential life lost-United States, 1984. MMWR 1997; 46:444-51.

9 Herdman R, Hewitt M, Laschober M. Smoking-related deaths and financial costs: Office of Technology Assessment estimates for 1990. Washington, DC: Office of Technology
maths and financial costs: Offe of Technology Assessment estimates for 1990. Wash

10 US Centers for Disease Control and Prevention. Medicalcare expenditures attributable to cigarette smoking United States, 1993. MMWR 1994;43:469-72.

11 Gale F. Tobacco dollar and jobs. Tobacco situation and outlook report. Washington, DC: USDA, 1997. (TBS-240.)

12 US Department of Agriculture. Tobacco situation and outlook report. Washington, DC: USDA, 1997. (TBS-238.)

13 US Centers for Disease Control and Prevention, Office on Smoking and Health. <http://www.cdc.gov/tobacco>, July 1997.

14 Sumner DA, Alston JM. Consequence of elimination of the tobacco program. Raleigh, North Carolina: North Carolina State University, 1984. (Agricultural Research Service bulletin No. 469.)

15 Gale F. What tobacco farming means to local economies. Washington, DC: USDA, 1994. (Agricultural economic repor No. 684.)

16 Warner KE. Tobacco subsidy: does it matter? F Natl Cancer Inst 1988;80:81-3.

17 Capehart T. Tobacco program - a summary and update.Tobacco situation and outlook report. Washington, DC: USDA, 1997. (TBS-238.)

18 Womach J. Tobacco price support: an overview of the program. $C R S$ report for Congress. Washington, DC: Congressional CRS report for Congress. Washington, DC:
Research Service, 1995. (95-129 ENR.)

19 Grise VN. The changing tobacco user's dollar. Tobacco situation and outlook report. Washington, DC: USDA, 1992. (TBS-219.)

20 Speccomm International Inc. The 1995 Maxzell tobacco fact book. Raleigh, North Carolina: Speccomm International Inc, 1996.

21 Keeler TE, Hu T-W, Barnett PG, et al. Do cigarette producers price-discriminate by state? An empirical analysis of local cigarette pricing and taxation. $\mathcal{f}$ Health Econ 1996;15:499-512.

22 Bray E, Mayo E. The economic welfare effect of the US peanut program. Paper presented at the Annual Meeting of American Agricultural Economics Association, Baltimore, Maryland, August 1992.

23 US Department of Agriculture. Tobacco situation and outlook report. Washington, DC: USDA, 1995. (TBS-233.)

24 Sumner DA, Wohlgenant M. Effect of an increase in the federal excise tax on cigarettes. Am $\mathcal{f}$ Agric Econ 1985;67:235-42.

25 Brown B. Cigarette taxes and smoking restrictions: impacts and policy implication. Am $\mathcal{F}$ Agric Econ 1995;77:946-51.

\section{Appendix}

The impact of policies designed to reduce smoking, such as federal cigarette tax increases, on revenues for quota owners and tobacco farmers is presented in figure 1 .

Before the policy change, the tobacco quota is set at level $Q_{f}$ and the quantity of tobacco demanded and supplied is equal at price level $\mathrm{P}_{\mathrm{s}}$. The net price received by tobacco farmers at quota level $Q_{f}$ is $P_{f}$, which equals their marginal costs of production. The difference between the market price $\mathrm{P}_{\mathrm{s}}$ and the marginal costs of production $\mathrm{P}_{\mathrm{f}}$ is the quota rent $\mathrm{P}_{\mathrm{s}} \mathrm{P}_{\mathrm{f}}$, which is the amount the tobacco farmer pays to tobacco quota owners for the production right. At quota level $Q_{f}$, the total farm revenue, which includes revenues for both tobacco farmers and quota holders, equals $\mathrm{P}_{\mathrm{s}} \mathrm{AQ}_{\mathrm{f}} \mathrm{O}$, with $\mathrm{P}_{\mathrm{s}} \mathrm{ACP} \mathrm{P}_{\mathrm{f}}$

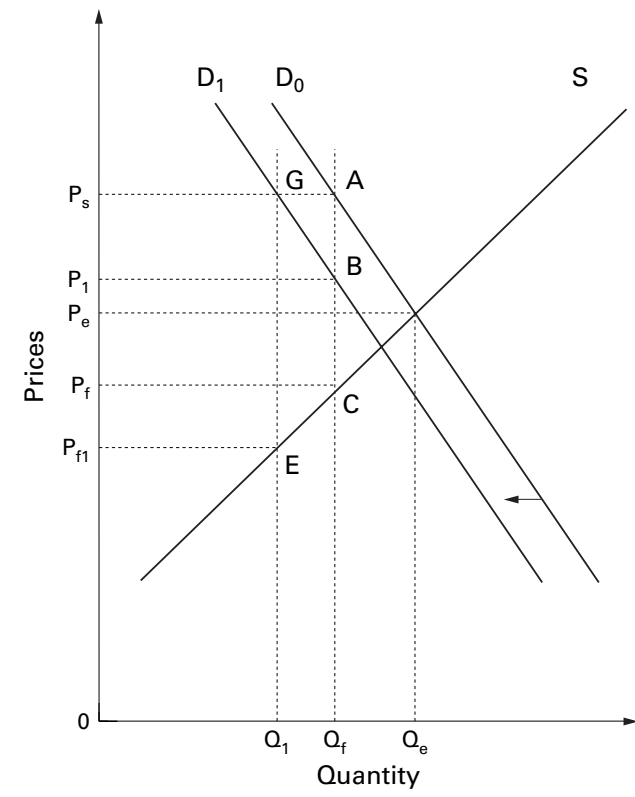

Impact of policies designed to reduce smoking on revenues for quota owners and tobacco farmers. $D_{0}$ and $D_{1}=$ demand curves for tobacco; $S=$ supply curve; $Q$ values $=$ various quantities of tobacco demanded and supplied; $P$ values = various levels of tobacco prices; $A, B, C, E, G$ $O=$ different intersection points (see text).

for quota owners and $\mathrm{P}_{\mathrm{f}} \mathrm{CQ}_{\mathrm{f}} \mathrm{O}$ for tobacco farmers.

The initial demand curve for tobacco, labeled $\mathrm{D}_{0}$, would shift left to $\mathrm{D}_{1}$ as a result of a reduction in smoking. In response to the decline in demand, the federal government can: (1) fix the quantity of quota and allow the level of price supports to fall; (2) maintain the level of price support and reduce the level of the tobacco quota; (3) adopt a policy that combines policy 1 with policy 2 (simultaneously reduce the level of price supports and the level of tobacco quotas).

Different policy selections will affect revenues for quota owners and tobacco farmers differently. If the government chose policy 1 , the market price of tobacco would fall from $P_{s}$ to $P_{1}$. The quota rent would fall from $P_{s} P_{f}$ to $P_{1} P_{f}$, the same absolute amount as the decline in the market price. The net price received by tobacco farmers would be unchanged at $P_{\mathrm{f}}$. The revenue for quota owners resulting from a reduction in smoking would fall by the amount $\mathrm{P}_{\mathrm{s}} \mathrm{ABP}_{1}$, the same as the reduction in total farm revenue. The net revenue for tobacco farmers would be unchanged at $\mathrm{P}_{\mathrm{f}} \mathrm{CQ}_{\mathrm{f}} \mathrm{O}$.

If the government chose policy 2 , the quota level has to be reduced to level $Q_{1}$ to sell all tobacco being produced at price $\mathrm{P}_{\mathrm{s}}$. In this case, the market price for tobacco would be unchanged at $\mathrm{P}_{\mathrm{s}}$, and the quota rent would increase by an amount $\mathrm{P}_{\mathrm{f}} \mathrm{P}_{\mathrm{fl}}$, which is the same as the decline in the net price received by tobacco farmers. Total farm revenue would change from $\mathrm{P}_{\mathrm{s}} \mathrm{AQ}_{\mathrm{f}} \mathrm{O}$ to $\mathrm{P}_{\mathrm{s}} \mathrm{GQ}_{1} \mathrm{O}$. The revenue for quota owners would change from $\mathrm{P}_{\mathrm{s}} \mathrm{ACP}_{\mathrm{f}}$ to $P_{s} G P_{f 1}$. The net revenue for tobacco farmers would fall from $\mathrm{P}_{\mathrm{f}} \mathrm{CQ}_{\mathrm{f}} \mathrm{O}$ to $\mathrm{P}_{\mathrm{fl}} \mathrm{EQ}_{1} \mathrm{O}$ with a net loss of $\mathrm{P}_{\mathrm{f}} \mathrm{CEP}_{\mathrm{f} 1}$. 
If the government adopted policy 3, the quota level would be set at a level between $Q_{f}$ and $Q_{1}$, and the quantity of tobacco demanded would equal the quantity of tobacco supplied at a price between $P_{s}$ and $P_{1}$. The lease rate for quota owners would lie somewhere between $\mathrm{P}_{\mathrm{s}} \mathrm{P}_{\mathrm{f}}$ and $\mathrm{P}_{\mathrm{s}} \mathrm{P}_{\mathrm{f} 1}$, while the net price received by tobacco farmers would be somewhere between
$P_{f}$ and $P_{f 1}$. The change in total farm revenues would be between $\mathrm{P}_{5} \mathrm{AQ}_{f} \mathrm{O}$ and $\mathrm{P}_{5} \mathrm{PQ}_{1} \mathrm{O}$. The revenue for quota owners would change to somewhere between the fall of $\mathrm{P}_{\mathrm{s}} \mathrm{ABP}_{1}$ and an increase equal to $\mathrm{P}_{\mathrm{s}} \mathrm{GEP}_{\mathrm{f} 1}$ less $\mathrm{P}_{\mathrm{s}} \mathrm{ACP}_{\mathrm{f}}$. Changes in the net revenue for tobacco farmers would lie somewhere between the no-change and the reduced $\mathrm{P}_{\mathrm{f}} \mathrm{CEP}_{\mathrm{f} 1}$.

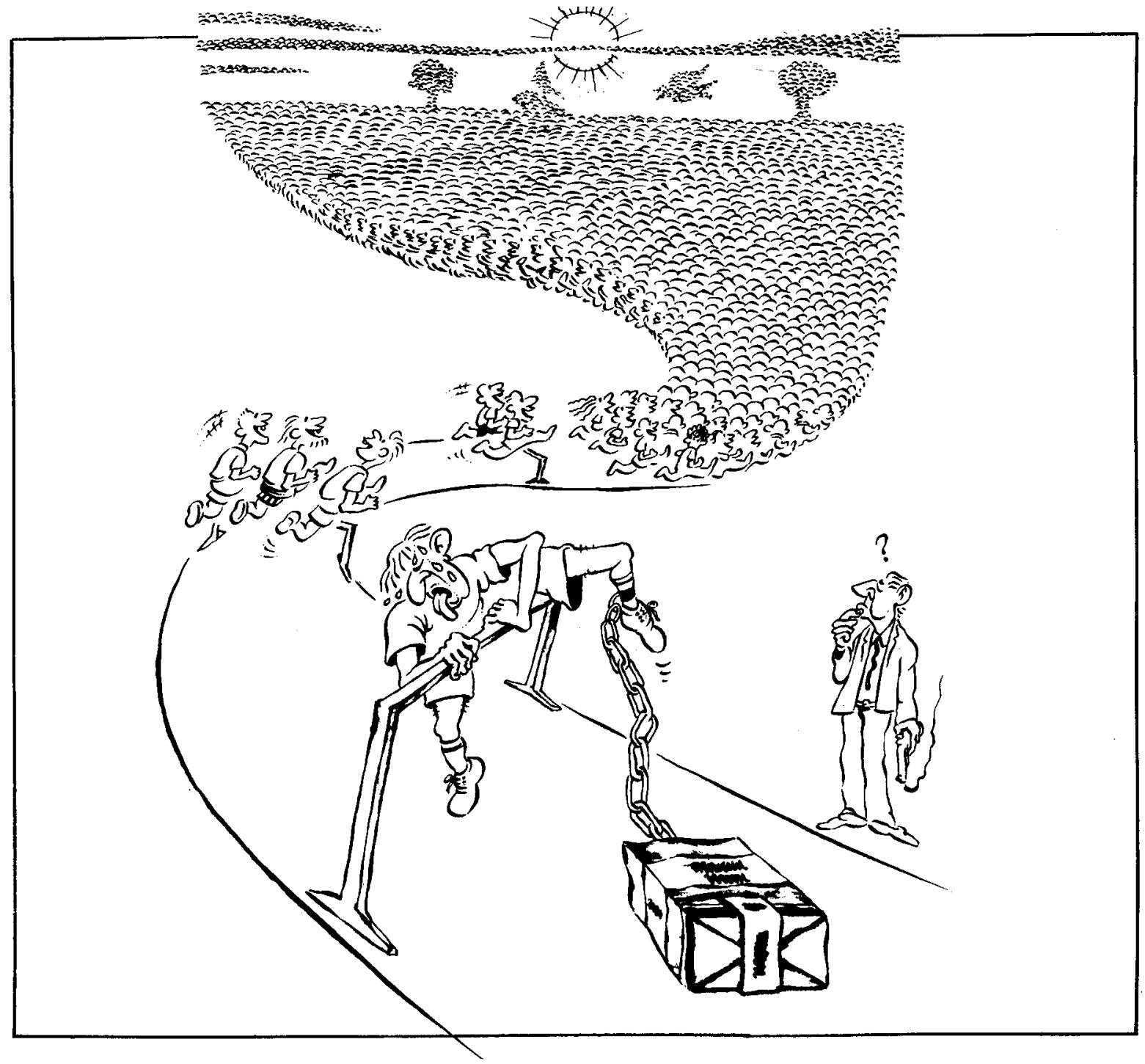

By Kadir Cengiz (Turkey) 